\title{
Application of instrumented nanoindentation in preformulation studies of pharmaceutical active ingredients and excipients
}

\author{
MATEJA EGART \\ BILJANA JANKOVIĆ* \\ STANE SRČIČ \\ Faculty of Pharmacy \\ University of Ljubljana \\ 1000 Ljubljana, Slovenia
}

Accepted January 11, 2016

Published online May 25, 2016

\begin{abstract}
Nanoindentation allows quantitative determination of a material's response to stress such as elastic and plastic deformation or fracture tendency. Key instruments that have enabled great advances in nanomechanical studies are the instrumented nanoindenter and atomic force microscopy. The versatility of these instruments lies in their capability to measure local mechanical response, in very small volumes and depths, while monitoring time, displacement and force with high accuracy and precision.

This review highlights the application of nanoindentation for mechanical characterization of pharmaceutical materials in the preformulation phase (primary investigation of crystalline active ingredients and excipients). With nanoindentation, mechanical response can be assessed with respect to crystal structure. The technique is valuable for mechanical screening of a material at an early development phase in order to predict and better control the processes in which a material is exposed to stress such as milling and compression.
\end{abstract}

Keywords: instrumented nanoindentation, mechanical properties, Young's modulus, indentation hardness, fracture toughness, crystalline active ingredients and excipients

\section{INTRODUCTION}

Successful formulation and production of solid dosage forms requires an understanding of the ingredients' (active or inactive) physical and chemical characteristics, including also mechanical properties which dictate how blends will behave during subsequent processing (tableting, milling, roller compaction, coating) (1-4).

Reliable quantification of mechanical properties (elasticity, plasticity, fragmentation) can be useful when choosing a processing method (i.e. granulation, direct compression), in the selection of excipients for improvement of poor blend compressibility, to elucidate defects such as capping or lamination and eventually to avoid unacceptable product dam-

\footnotetext{
* Correspondence; e-mail: biljana.jankovic@ffa.uni-lj.si

* Dedicated to Prof. Dr. Jelka Šmid Korbar at the occassion of her $80^{\text {th }}$ birthday.
} 
age during packing and distribution (5-7). In high drug load tablet formulations, excipients cannot completely circumvent the poor compression properties of the active pharmaceutical ingredient (API). In such cases, modification of intrinsic API properties through formation of salts, alternative polymorphic forms, hydrates, solvates and cocrystals should be taken into consideration (8-12). Because the drug substance is available only in small quantities in the preformulation phase, instruments and techniques that can evaluate its properties and identify potential critical attributes would be preferred. Nanoindentation, the way to predict processability of a material exposed to deformational stress, has made this possible since measurements can be conducted at the level of single crystals or particles. Articles focusing on mechanistic understanding of elastic, plastic deformation and fragmentation were excluded from the current review since this was extensively reported in the literature (13-17). The article primarily describes application of instrumented nanoindentation for mechanical characterization of crystalline active and active and inactive ingredients in pharmaceutical technology.

\section{HOW CAN MECHANICAL PARTICLES BE DETERMINED IN PRACTICE?}

Experimental approaches for determining mechanical properties of pharmaceutical materials can be classified as compacts and single particle measurements. Tests evaluating the mechanical properties on compacts include bending (three- and four-point), microindentation and compression tests (3-4, 18-29). The main characteristics of mechanical characterization on compacts are the following: the materials have already been deformed during sample preparation; a large amount of materials is needed for formation of compacts; mechanical properties of particle assembly are determined (30-34).

Determination of mechanical particles at the single particle level can be accomplished with high-resolution instruments such as an atomic force microscope (AFM) and an instrumented nanoindenter (35-39). Since these measurements are influenced by surface properties, the obtained results have to be supported with complementary techniques such as high-pressure diffraction (40-43) or simulation approaches based on determination of crystal interplanar d-spacings, attachment or surface energy (44-47).

From another point of view, the methods for mechanical evaluation of pharmaceutical materials can be divided into static and dynamic (19). Static methods are based on direct measurements of stresses and strains during mechanical tests and include most of the tests mentioned herein. Dynamic techniques, on the other hand, are classified as resonance and pulse methods and are preferentially used when mechanical properties of viscoelastic or viscoplastic materials are measured $(19,25)$.

\section{NANOINDENTATION}

Nanoindentation uses the recorded depth of penetration of an indenter (tip) into the specimen along with the measured applied load to determine the area of contact and thereby hardness $(H)$ of the investigated sample. Numerous mechanical properties can be obtained from the experimental load-displacement curve, the most relevant being Young's modulus $(E)$. Other parameters such as fracture toughness $\left(K_{\mathrm{IC}}\right)$, yield pressure $\left(P_{\mathrm{y}}\right)$ and residual stress can be subsequently calculated or derived from the determined $E$ and $H$ values. 


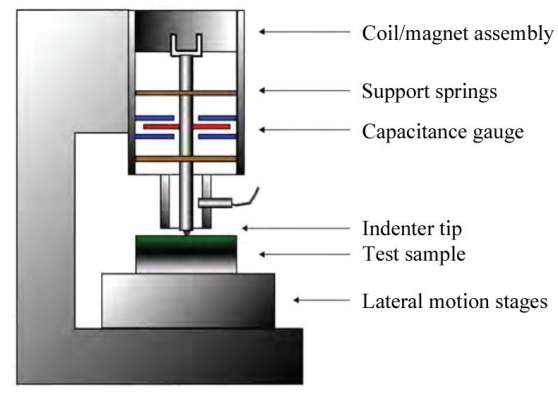

Fig. 1. Schematic of the Nanoindenter G200 (image courtesy of Keysight Technologies) (65).

The method is based on accurate determination of the initial contact of the indenter with the sample surface, correction for compliance of the loading frame and tip geometry, as well as material-related phenomena such as pile-up, sink-in, indentation size effect, etc. Review articles and handbooks provide a good starting point for basic principles of the method $(35,38,39,48-61)$. However, it is the author's experience that there is a common set of misconceptions and errors in the application of nanoindentation in pharmaceutical technology. Therefore, the present paper seeks to highlight the best available practice of nanoindentation in characterization of mechanical properties of crystalline active and inactive ingredients.

Table I. Indenter tips and their characteristics (image courtesy of Keysight Technologies) (56)
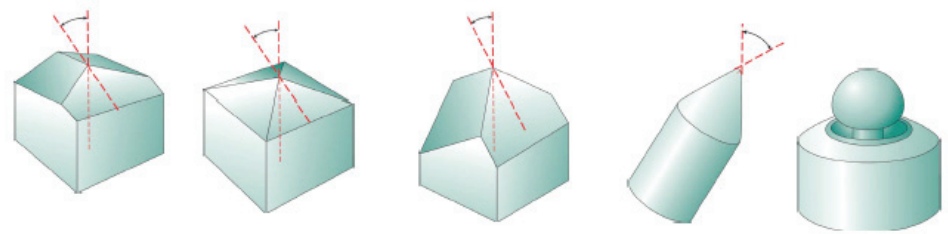

\begin{tabular}{lccccc}
\hline Features & Berkovich & Vickers & Cube-Corner & $\begin{array}{c}\text { Cone } \\
\text { (angle } \psi \text { ) }\end{array}$ & $\begin{array}{c}\text { Sphere } \\
\text { (radius) }\end{array}$ \\
\hline Shape & 3-sided pyramid & 4-sided pyramid & $\begin{array}{c}\text { 3-side pyramid/ } \\
\text { perpendicular faces }\end{array}$ & Conical & Spherical \\
\hline $\begin{array}{l}\text { Bulk materials, } \\
\text { Thin films, } \\
\text { tions }\end{array}$ & $\begin{array}{c}\text { Polymers, Scratch } \\
\text { testing, Wear } \\
\text { testing, Imaging }\end{array}$ & $\begin{array}{c}\text { Bulk materials, } \\
\text { Silms and foils, } \\
\text { Wear testing }\end{array}$ & $\begin{array}{c}\text { Thin films, Scratch } \\
\text { testing, Fracture } \\
\text { toughness, Wear } \\
\text { testing, Imaging }\end{array}$ & $\begin{array}{c}\text { Scratch } \\
\text { testing, } \\
\text { Imaging }\end{array}$ & $\begin{array}{c}\text { Viscoelastic } \\
\text { materials }\end{array}$ \\
\hline $\begin{array}{l}\text { Face } \\
\text { angle, } \alpha\end{array}$ & $65.3^{\circ}$ & $68^{\circ}$ & $35.2644^{\circ}$ & - & - \\
\hline $\begin{array}{l}\text { Area } \\
\text { (projected) }\end{array}$ & $24.56 h_{\mathrm{c}}^{2}$ & $24.504 h_{\mathrm{c}}^{2}$ & $2.5981 h_{\mathrm{c}}^{2}$ & $\pi \mathrm{a}^{2}$ & $\pi \mathrm{a}^{2}$ \\
\hline
\end{tabular}


Sample properties are the key for obtaining relevant results; hence, the best system for investigation involves single crystals and particles, as well as polymeric films. Measurements on nm level are influenced by surface properties (defects, cracks, and flaws); thus, significant dissipation of the results can be observed when probing heterogeneous materials or composite structures. In order to reliably predict mechanical behavior at the bulk level (granules, tablets), a statistically valid sample size within nanoindentation measurements should be assured (minimal number of repetitions is 25 with the relative standard deviation within measurements less than $10 \%$ ) (62). From a quality perspective, tests with instrumented nanoindenters (Fig. 1) are supported by ISO (14577) and ASTM standards (E2546), and hence govern equipment, calibration, test methods, analysis and reporting concepts $(63,64)$.

The most common indenter tip used for analysis is the Berkovich tip. Berkovich indenter is recommended in practice owing to its numerous advantages such as uniformity of its shape from vendor to vendor (reproducible face angles can be produced with high accuracy), sharpness of the tip apex in the range of $20 \mathrm{~nm}$ in diameter and production of plasticity at small displacements without producing cracks. Additional geometries of the tips along with their properties are represented in Table I $(35,52,54-56)$.

Recently developed techniques to be performed with nanoindenters are listed below:

- Continuous stiffness measurement (CSM) allows continuous determination of $E$ and $H$ during loading rather than just at the final point of stress. This is beneficial when examining materials with anisotropic characteristics $(49,54)$.

- Dynamic contact measurement (DCM-CSM) allows ultra-low-load mechanical property characterization (max. load $10 \mathrm{mN}$ ). This option has improved resolution in force (load resolution $1 \mathrm{nN}$ ) and displacement (displacement resolution 0.0002 $\mathrm{nm})$, as well as reduced sensitivity to environmental vibrations.

- Lateral force approach allows measurement of forces in the x-y plane to the indenter column. During the scratch test, these forces correspond to the tangential frictional and the lateral scratch forces. With a tangential force sensor, nanoscratch and wear tests can be performed at ramping loads $(54,65-66)$.

\section{Contact mechanics and model for fitting load-displacement data}

A typical result obtained from a nanoindentation experiment is the load-displacement curve, as depicted in Fig. 2. Hertz postulated the model for description of purely elastic contact between spherical surfaces (67). The most significant contribution of Hertzian contact mechanics is the definition of contact radius $a$ according to Eq. 1:

$$
a^{3}=\frac{3}{4} \frac{P R}{E_{\mathrm{r}}}
$$

where $P$ represents applied load, $R$ is combined radius and $E_{\mathrm{r}}$ describes reduced elastic modulus. From the nanoindentation point of view, the relation between $E$ of a sample can be expressed by taking into consideration $E$ from the indenter tip (generally made of hard material such as diamond) (Eq. 2):

$$
\frac{1}{E_{\mathrm{r}}}=\frac{1-v_{\mathrm{s}}^{2}}{E}+\frac{1+v_{\mathrm{i}}^{2}}{E_{\mathrm{i}}}
$$

where $E_{\mathrm{i}}$ and $v_{\mathrm{i}}$ are known values of $E$ and Poisson's ratio of the specific indenter, $E$ and $v_{\mathrm{s}}$ are the same parameters for the sample $(48,49)$. 


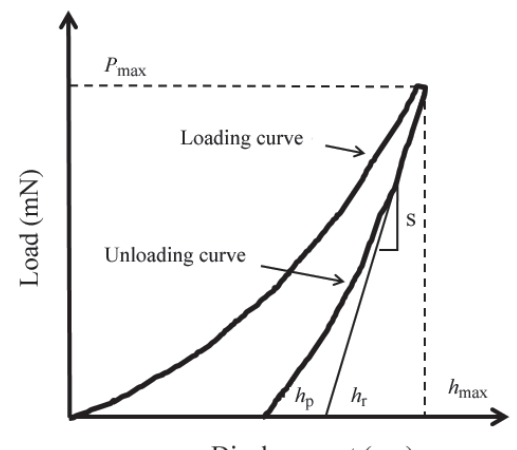

Displacement (nm)

Fig. 2. Load-displacement curve obtained in a nanoindentation experiment $\left(h_{\mathrm{p}}\right.$ - permanent depth after removal of test force; $h_{\mathrm{r}}$-intersection of the tangent to the first part of the unloading curve with the displacement axis; $h_{\max }$ - indenter displacement at peak load) $(35,48)$.

It is important to elucidate the transition from purely elastic contact to plastic contact using the Berkovich indenter. Once the indentation depth surpasses the tip radius, the geometry of the indenter becomes a dominant factor, which contributes to plastic deformation at the contact point. At maximal load, a hold period is often applied to minimize the creep effect before the indenter is unloaded. Creep represents the time-dependent plastic deformation, which occurs due to the movement of the material within a specimen under high pressure in the contact zone. Besides applying a hold period prior to unloading, creep can be mitigated by decreasing the strain rate less than $1 \%$ per minute (68) or by using effective contact stiffness (S) proposed by Feng and Ngan (Eq. 3) (69):

$$
\frac{1}{S}=\frac{1}{S_{\text {app }}}+\frac{h_{\mathrm{d}}}{\left|F_{\mathrm{u}}\right|}
$$

where $S_{\text {app }}$ - apparent contact stiffness, $h_{\mathrm{d}}$ - indenter velocity at the end of dwell, $F_{\mathrm{u}}-$ load decrease rate at the beginning of unloading.

The mechanical property calculated from the load-displacement curve can be additionally influenced by thermal drift. Thermal drift is the main reason for changes in the dimension of the contact zone as a consequence of thermal expansion or contraction induced by temperature changes. In general, it can be reduced by controlling the environmental conditions or by establishing thermal equilibrium for a sufficiently long time after handling before the test $(35,55,65)$.

During the decompression phase, materials demonstrate a certain level of elastic recovery as the material outside the plastic zone relaxes and seeks to resume its original shape. On the load-displacement curve, elastic relaxation is evidenced by a reduction in indentation depth with decreasing load. The unloading behavior is presumably an elastic affair since reversible plasticity does not exist. Therefore, the slope of the unloading curve represents contact stiffness $(S)$.

More precisely, $S$ is defined as the slope of the upper portion of the unloading curve where elastic deformation prevails (Eq. 4). 


$$
S=\left(\frac{d P}{d h}\right)
$$

The most widely used model for analyzing the load-displacement curve (model for contact depth) was developed by Oliver and Pharr $(48,49)$. The Oliver-Pharr data analysis begins by fitting the initial unloading curve to the power-law relation based on Sneddon's equation (Eq. 5) (70).

$$
P=\alpha *\left(h-h_{\mathrm{p}}\right)^{m}
$$

where $\alpha$ is a constant depending on the material type, $m$ is a constant related to indenter geometry ( $m=1$ (flat punches); $m=1.5$ (spherical and parabolic indenter); $m=2$ conical indenter), and $h_{\mathrm{p}}$ is permanent indentation depth after withdrawal of the indenter.

The area of contact at peak load is determined by the geometry of the indenter and the depth of contact, $h_{\mathrm{c}^{\prime}}$ where $h_{\mathrm{c}}$ is determined according to Eq. 6 .

$$
h_{\mathrm{c}}=h_{\max }-\varepsilon\left(\frac{P_{\max }}{S}\right)
$$

$\varepsilon$ is a constant dependent on the indenter shape. For cones $\varepsilon$ is 0.72 and for spheres $\varepsilon$ is 0.75 . The value of $\varepsilon=0.75$ is used for the Berkovich indenter.

The projected contact area $\left(A_{\mathrm{p}}\right)$ that is used to calculate $E_{\mathrm{r}}$ and $H$ is a function of the indenter's contact depth $\left(h_{\mathrm{c}}\right)$ with the tested sample at $P_{\text {max. }}$. For example, $A_{\mathrm{p}}$ for the Berkovich indenter is calculated according to Eq. 7:

$$
A_{\mathrm{p}}=24.56 h_{\mathrm{c}}^{2}
$$

Reduced Young's modulus $\left(E_{r}\right)$ of the indentation contact is given by $E q .8$ and is obtained as a result of nanoindentation measurement:

$$
E_{r}=\frac{\sqrt{\pi}}{2 \beta} \frac{S}{\sqrt{A_{\mathrm{p}}\left(h_{\mathrm{c}}\right)}}
$$

where $\beta$ is a factor that depends on the indenter shape (Berkovich indenter: $\beta=1.034$ ) and accounts for the fact that elastic deformation occurs both in the sample and indenter.

\section{Indentation hardness $(H)$}

$H$ can be calculated from Eq. 9 as the ratio between the applied load $\left(P_{\max }\right)$ and projected contact area $\left(A_{\mathrm{p}}\right)$ :

$$
H=\frac{P_{\max }}{A_{\mathrm{p}}}
$$

The most common necessary corrections upon calculation of data from nanoindentation curves are the initial contact point, frame compliance and indenter area function. Their impact and involvement in the method as well as the calculation procedure are described elsewhere $(35,48,49)$. The material-related characteristics are difficult to be com- 
pensated and represent the indentation size effect, pile-up as well as sink-in of material around/inside residual impression. The presence of discontinuities (sudden increase of displacement at the same load) in the load-displacement response defined as pop-ins is indicative of fracturing, delamination or plastic deformation, which is intermittent in nature $(35,71)$. Another possibility of pop-in effect can be correlated with nucleation of dislocations in a perfect crystal or rapid multiplication of dislocations (71). The model for time dependent response and indentation response of coated components will not be a topic of the current review.

\section{Pile-up and sink-in}

Contact depth $\left(h_{c}\right)$ according to Eq. 6 is derived from maximal indentation depth, which takes into account $\varepsilon=0.75$ as being present in purely elastic contact. Based on that model, the material around the indenter sinks down. On the other hand, ductile samples are generally squeezed out upward the residual impression (Fig. 3). In such cases, the

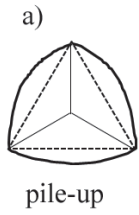

b)

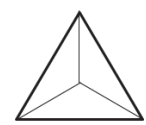

no pile-up or sink-in c)

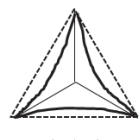

sink-in d)

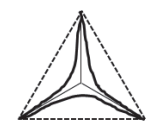

excessive sink-in

Fig. 3. Schematic of Berkovich residual impressions representing different degrees of pile-up and sink-in. If the residual impressions exhibit pile-up (a) or extensive sink-in (d), the Oliver-Pharr model will underestimate or overestimate the contact depth, respectively (adapted from reference 76).

contact area appears larger and materials seem to be stiffer, which underestimates the values of $E$ and $H$. The most important predictor of pilling up is the ratio between $E$ and $P_{\mathrm{y}}$. High $E / P_{\mathrm{y}}$ ratio is related to the large plastic zone and significant degree of material surrounding the indenter, which could consequently be displaced upward along the plastic flow. A certain percent of pharmaceutical materials possess strain-hardening properties (72-74). In such cases, the material becomes harder with subsequent plastic deformations, which constrains its upward flow. A simple approach for assessment of pile-up propensity of materials is the ratio of the final indentation depth of the impression after unloading to the total depth under load $\left(h_{\mathrm{f}} / h\right)$. Pile-up is significant if $h_{\mathrm{f}} / h \geq 1.0(49,75)$.

\section{Indentation size effect}

Indentation size effect (ISE) was first reported in metals, detected as an increase of indentation hardness by decreasing the depth of penetration regardless of the indenter shape geometry $(77,78)$. The reasons can be divided into methods and material used. Berkovich indenter is pyramidal in shape, although bluntness or spherical shape is present at its tip. As a consequence, the actual contact area for very small distances from the tip is much larger (spherical impression) than the same distance for an ideal indenter (pyrami- 
dal residual impression). For a given load, indenter penetration is thus smaller, and hardness appears to be higher. The mostly accepted mechanistic understanding of ISE, adopted for pharmaceutical crystalline materials, is related to the presence of dislocations and their density distribution in the structure. If the indentation depth is pronounced, the affected volume contains many dislocations, and the plastic flow is unaffected to this depth. If the extent of indentation is comparable with the distance between dislocations, fewer dislocations are present, and the average contact stress for the initiation of plastic flow must be higher $(51,77)$. Dependence of mechanical properties on the indentation depth was proposed by Nix and Gao (Eq. 10) (79):

$$
H=H_{0} 1+\left(\frac{h^{*}}{h}\right)^{1 / 2}
$$

where $H$ is hardness for a given depth of indentation $(h), H_{0}$ is macro-hardness (related to large penetration depth) and $h^{*}$ is the characteristic length that depends on the shear modulus, $H_{0}$ and tip shape (79).

In case of pharmaceutical materials, ISE can be also related to their viscoelastic properties, and can be mitigated by the use of flat tips.

\section{Indentation rules of thumb}

Results of mechanical nanoindentational testing can only be as good as the sample used for testing. Over the years, a set of generalized rules associated with sample properties have been empirically determined as the "three rules of thumb," including the $10 \%$ rule for indentation depth, the $5 \%$ rule for surface roughness, and the 1-degree rule for surface tilt and alignment (80-83). These rules are also listed as requirements in the ISO standard for instrumented indentation testing (82).

The $10 \%$ rule means that independent measurements of sample hardness can be made up to $10 \%$ of penetration into the sample (substrate independent hardness measurement). This rule applies to a wide range of material behavior and is generally used. The 5 $\%$ rule postulates that surface roughness should be no more than $5 \%$ of the depth at which results are obtained in order to obtain relevant results $(E q$. 11). Sample roughness can lead to large errors in the contact area which is directly used in determination of $H$ and its square root for $E$. Therefore, $H$ is more affected by sample roughness than the $E$. It has been shown that repeatable and reliable measurements can be made at penetration depths less than the minimum depth specified by the $5 \%$ rule but in such cases larger scatter of the results should be expected $(81,83)$.

$$
h_{\min }=\frac{\text { surface roughness }}{0.05}
$$

Finally, the 1-degree rule should be considered when testing surfaces that are not aligned orthogonally to the indenter. The sample surface should be within 1 degree of orthogonal alignment with the tip, otherwise determination of the contact area is not adequate, with possible lateral sliding of the contact. It was shown that with increasing the offset angle both $H$ and $E$ values were higher as a result of increased contact area (81, 83). 
An option to circumvent the problems associated with the substrate and surface effects on determination of mechanical parameters is the continuous stiffness measurement technique. This technique enables a clear determination when substrate influences are affecting the data and identification of the region where relevant data are obtained (82).

\section{Continuous stiffness measurement}

Continuous stiffness measurement (CSM) is an improvement upon the traditional nanoindentation method. With CSM, stiffness is continuously measured during the loading. Therefore, $E$ and $H$ are determined as a function of penetration depth. This is accomplished by imposing a small dynamic oscillation in the force (or displacement) signal and measuring the amplitude and phase of the corresponding displacement (or force) with a frequency-specific amplifier. The calculation principle is based on a simple harmonic oscillator subjected to force oscillation according to Eq. 12:

$$
K=\left(S^{-1}+K_{f}^{-1}\right)+K_{\mathrm{s}}
$$

where $K$ is equivalent stiffness, which includes contact stiffness $S$, load-frame stiffness, $K_{f \prime}$ and the stiffness of support springs, $K_{\mathrm{s}}$.

Sample stiffness $(S)$ and contact damping $\left(D_{\mathrm{s}} \omega\right)$, given by Eqs. 13 and 14, are continuously measured during indentation.

$$
\begin{gathered}
S=\left(\frac{1}{\frac{F_{0}}{z_{0}} \cos \varnothing-\left(K_{\mathrm{s}}-m \omega^{2}\right)}-\frac{1}{K_{\mathrm{f}}}\right)^{-1} \\
D_{\mathrm{s}} \omega=\frac{F_{0}}{z_{0}} \sin \phi-D_{\mathrm{i}} \omega
\end{gathered}
$$

In these equations, $m, K_{\mathrm{s}} K_{\mathrm{f}}$ and $D_{\mathrm{i}}$ are all machine parameters, where $m$ is indenter column, $K_{\mathrm{s}}$ is stiffness of the support spring, $D_{\mathrm{i}}$ is the damping factor of indenter head, and $K_{\mathrm{f}}$ is stiffness of the load frame. Machine parameters $m, K_{\mathrm{s}}$ and $D_{\mathrm{i}}$ are determined by analyzing the dynamic response of the system when the indenter is hanging free. In the experiment, excitation frequency of the force $(\omega)$ is a set value. During experiments, we measure the displacement amplitude $\left(z_{0}\right)$, phase angle $\varphi$, and excitation amplitude $F_{0}$.

The CSM technique offers the following advantages: it provides continuous measurement of elasticity and plasticity as a function of indentation depth; the time required for measurement is reduced because there is no need for multiple loading and unloading; and the contact point is more accurately determined $(49,54,57,65,84)$.

\section{Fracture behavior}

Fracture behavior can be quantitatively evaluated with fracture toughness $\left(K_{\mathrm{IC}}\right)$. It represents the material's resistance to fracturing. When a material has a low $K_{\mathrm{IC}}$, it can be considered brittle and more prone to fracturing. In pharmaceutical technology, this pa- 


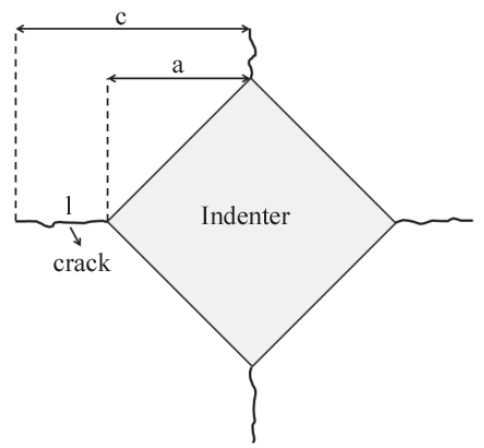

Fig. 4. Scheme of a radial crack caused by Vickers indenter (adapted from reference 88).

rameter is important as the prediction factor for the milling process. Calculation of $K_{\mathrm{IC}}$ is commonly based on the use of a Vickers indenter because the Vickers indenter has a sharper tip compared to the Berkovich type of indenter, which can more easily form a crack at smaller indentation loads. Crack lengths are usually in the range of $0.5-10 \mu \mathrm{m}$ and are determined either by SEM (scanning electron microscopy), scanning nanoindenter tip or AFM (atomic force microscopy) (85). Even with sharp indenter tips like Vickers, the solid sometimes does not crack which could be the case in softer materials. For such materials, estimation of $K_{\mathrm{IC}}$ is not possible (51). Different models are used to calculate $K_{\mathrm{IC}}$ and are discussed in an article by Shiffmann. All models make assumptions about crack geometry, which influences the crack area considered in equations (85). Fracture toughness for the most frequently used Vickers and Berkovich indenters can be calculated according to Eq. 15 (Fig. 4).

$$
K_{I C}=x_{v}\left(\frac{a}{l}\right)^{1 / 2}\left(\frac{E}{H}\right)^{2 / 3} P / c^{3 / 2}
$$

where $x_{\mathrm{v}}$ is a calibration constant of the indenter, $a$ is the indent diagonal, $l$ is the length of a crack, $E$ is Young's modulus, $H$ is hardness, $P$ is load, and $c$ is the crack radius given by $a+l$ $(16,33,86,87)$.

An additional parameter used to describe fracture properties is the brittleness index (BI) (Eq. 16).

$$
B I=\frac{H}{K_{\mathrm{IC}}}
$$

Using $B I$, materials can be categorized as easy, moderate, and difficult to mill. Higher value of $B I$ (i.e., higher $H$ and lower $K_{\mathrm{IC}}$ ) promotes the fracturing of material during grinding. The theory behind this relates to lower energy required for plastic deformation, thus leaving more energy input for the creation of new surfaces, that is, crack growth and fracture. The same principle is true of low fracture toughness (less resistance to fracture), in which case less energy is needed to create new surfaces $(33,86,87)$.

By determining fracture parameters using nanoindentation, selection of milling conditions and mill types with a minimal amount of material can be attained $(33,86,87,89-91)$. The examples are described in detail in the section on »Nanoindentation in milling prediction $«$. 


\section{APPLICATION OF NANOINDENTATION IN PHARMACEUTICAL TECHNOLOGY}

\section{Mechanical properties of molecular crystals}

The type of deformation that happens in a crystal upon the application of mechanical stress is strongly dependent on the crystal structure and molecular packing. Plasticity in crystals is generally achieved through irreversible glide or slip, twinning, or bending of molecular layers (Fig. 5). Shearing or slipping is associated with the layered structure of a crystal, for which strong in-plane and non-specific interlayer interactions are characteristic. Slip planes in crystals frequently exhibit the largest d-spacing (inter-planar distances), accompanied with the lowest attachment energy. When exposed to mechanical stress, the molecules forming slip planes tend to slide as a whole. Plastic deformation due to twinning occurs in crystals with low symmetry and few slip systems or when plastic deformation is obstructed due to unfavorable alignment or under high loads. Unlike slip, twinning deformation is homogenous over the entire crystal lattice and is not restricted to multiples of the lattice parameter $(45,46,50,58,92-95)$. Compounds with a disordered, corrugated layered structure do not show shearing; they bend or break under applied mechanical stress. Bending occurs when the crystal packing is anisotropic, in which strong and weak interaction patterns happen in nearly perpendicular directions. Interactions in such crystals are not uniform and similar in all directions. Once bent, the crystal does not regain its original shape. This is called plastic bending $(45,58)$.

When crystals are defined as brittle, they can fracture more easily or break into pieces under mechanical stress. Molecules in such crystals are commonly highly interlocked, with isotropic interactions in all three dimensions of the structure $(50,96)$. Pharmaceutical materials such as molecular solids commonly exhibit anisotropic properties. Therefore, measuring and interpreting their mechanical properties can be quite demanding (58). In specific cases, at least 3 to 6 oriented crystals are necessary for investigation of crystal anisotropy, with a minimum of 20 repetitions within each. This number is generally sufficient to give a statistically representative sample size with acceptable scatter in the results (usually defined as a covariance lower than $10 \%$ ). Prior to measurements, crystals should be oriented on a single X-ray diffractometer and tightly bounded to substrate surface. Nevertheless, this rule is not limited and should include different statistical approaches related additionally to the size and surface quality of the prepared monocrystals $(62,81)$.

To investigate the mechanical behavior of single organic crystals with respect to their crystal structure, nanoindentation has recently gained considerable research attention (37,

a)

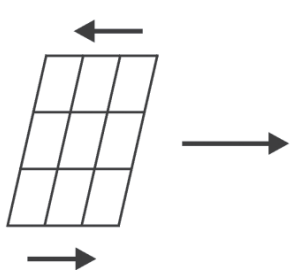

b)

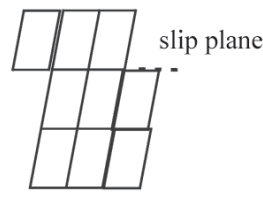

c)

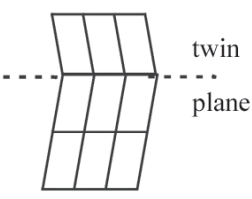

d)

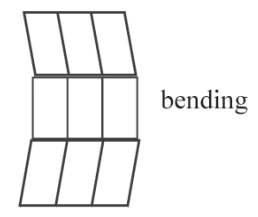

Fig. 5. Schematic presentation of crystal deformation upon mechanical stress: a) original crystal, b) slip, c) twinning, d) bending (adapted from reference 50). 
58, 71, 97, 101). Ramos and Bahr mechanically evaluated oriented sucrose crystals using nanoindentation. Sucrose is described as a brittle material containing few slip systems. The measured E ranged from $38 \mathrm{GPa}$ for the (100) crystal face to $33 \mathrm{GPa}$ at the dominant crystal face (001) and was in accord with sucrose orientation-dependent bonding strength, whereas $H$ was similar at both investigated faces $(1.5 \mathrm{GPa})$. It was suggested that solute molecular defects (such as water) could impact the measurement of $H$ and thus the environment should be an important consideration in the plastic deformation measurement (71).

Feng et al. focused on examining the differences in crystal structures of several parabens and their ability to form compacts. Instrumented nanoindentation was employed to quantitatively evaluate plasticity on the dominant face of parabens' single crystals (see Table III). According to the $H$ results, methyl paraben had the fewest plastic properties (highest $H$ ), and produced tablets of the lowest tensile strength compared to other parabens (ethyl, propyl, and butyl paraben). These results were in accord with their structural differences and correlated well with the absence of slip alignment (methyl paraben) or the presence of slip planes (ethyl, propyl, and butyl paraben) in their crystal structures. The increased surface area obtained by plastic deformation in parabens with slip planes caused more interactions between particles and thus the formation of stronger compacts (92).

In a study performed by our research group, APIs such as famotidine, nifedipine, olanzapine and piroxicam were selected for quantitative mechanical evaluation with instrumented nanoindentation. From the practical point of view, the most thermodynamically stable polymorphic forms were prepared, oriented and mechanically characterized. An exception was famotidine, for which both forms, A (thermodynamically most stable) and B (kinetically favored form), were included in the study. Form B is also the one used in marketed formulations. Mechanical attributes such as $E$ and $H$ were consistent with the molecular packing of the polymorphic forms investigated with respect to crystal orientation. Mechanically interlocked structures were characteristic of most of the tested APIs. In these cases, the response of different crystal faces to indentation was isotropic. For two polymorphic forms of famotidine, a distinct difference was found in their plastic behavior.

a)

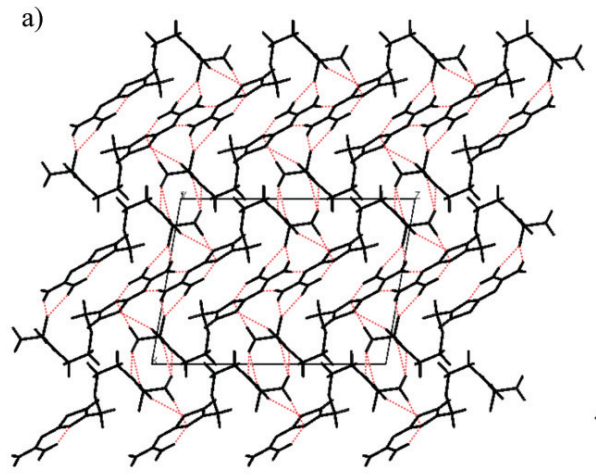

b)

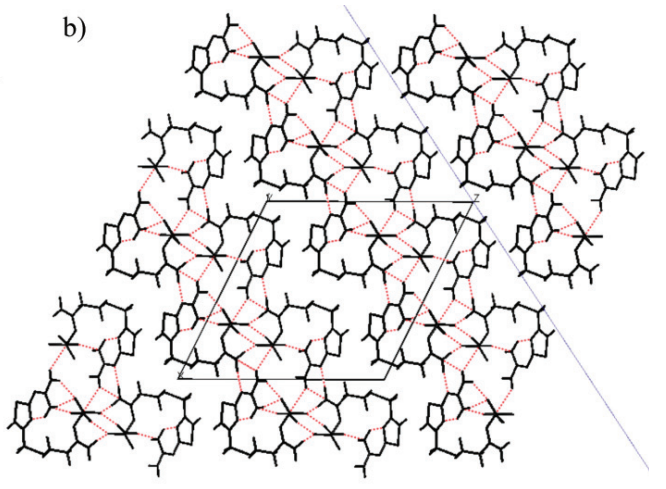

Fig. 6. Packing diagram of: a) famotidine A and b) famotidine B, viewed along the b-axis. Hydrogen bonds are shown as red dotted lines. The slip plane $(-101)$ in form B is represented as a blue line (98) (with permission from Springer). 
For famotidine A, the molecules were densely packed and highly cross-linked, which resulted in higher $H$ compared to form $\mathrm{B}$, for which the presence of a slip plane was confirmed, indicating its higher plasticity (Fig. 6).

Nanoindentation for form B was conducted in a direction normal to slip planes. Nevertheless, the attainable lower $H$ was explained by higher density in one direction, which decreased the attachment energy of stacking layers and stiffness but improved its plasticity. Deformational mechanism for the examined crystals was assessed according to yield pressure $\left(P_{\mathrm{y}}\right)$ and its ratios with $E$ and $H$ calculated from $E q .17$, as proposed by Roberts and Rowe (99). According to the $H / P_{\mathrm{y}}$ ratio, materials can be classified as very plastic if the value is 1.5-2.0; brittle when $H / P_{\mathrm{y}}$ is $2.0-2.2$, and plastic if $H / P_{\mathrm{y}} \geq 3$.

$$
\frac{H}{P_{\mathrm{y}}}=0.07+0.6 \ln \frac{E}{P_{\mathrm{y}}}
$$

Brittle behavior was determined in the case of highly cross-linked structures (98).

Nanoindentation was utilized by Varughese et al. in an examination of the differences in interaction anisotropy and shear instability of two known aspirin polymorphs, metastable form II and stable form I. The distinction between the two forms is related to the manner in which crystal layers are arranged. The structure of form I is related to that of II by a relative shift of adjacent layers parallel to one of the crystallographic axes. Because the two forms are related, indentation experiments were performed on potential slip planes in both forms: the (001) face of form I and the structurally equivalent (102) face of form II. Smooth load-displacement curves consistent with the induced slippage were characteristic for (001) of I and (102) of form II, while distinct pop-ins were observed for (100) of form I due to normally applied stress to the slip plane. Nanoindentation results revealed that the (102) face of the metastable polymorph II had lower $H$ and $E$ compared to the (001) face of the stable form I and was thus susceptible to elastic/plastic deformation. This result represented the mechanical rationale for the solid-state transformation of form II to form I. Under ambient conditions, this could take several months, but under shear stress (applied by milling) this process can be accelerated (37).

Olusanmi et al. extended their work also in investigating the deformation and breakage behavior of aspirin form I (31). They reported different propensities for crack propagation at different faces of aspirin crystal. Fracture toughness at the (001) plane was significantly lower compared to the (100) plane, indicating that the former (001) was the preferred cleavage plane for aspirin I. Measured $E$ and $H$ were lower on the (001) face compared to the (100) face, showing a higher tendency towards elastic/plastic deformation. When the same load was applied to the two main crystal faces, higher indentation depths were attained at the (001) face indicating easier plastic flow. Analyses of the load-displacement curves showed frequent but shallow pop-ins of the (001) face and comparatively deeper but less frequent pop-ins of the (100) face. It was concluded that pop-ins at the (100) face were associated with cracking while smooth or shallow pop-ins of the (001) crystal face suggested induced slippage (31). This study demonstrated that aspirin form I is anisotropic in its fracture and slip behavior.

Mishra et al. focused on alternation of deformational properties of odd and even $\alpha, \omega$ alkanedicarboxylic acids (diacids). Variation of $H$ and $E$ was examined by nanoindentation on the major faces of up to six single crystals. It was observed that $E$, as an intrinsic prop- 
M. Egart et al:: Application of instrumented nanoindentation in preformulation studies of pharmaceutical active ingredients and excipients, Acta Pharm. 66 (2016) 303-330.

erty, depended on the type and number of intermolecular interactions and molecular arrangements alternated with odd and even diacid series. These variations have already been observed for physical and thermal properties, like melting point, sublimation, and solubility. Even diacids can accommodate the stable sawtooth conformation with minimum $\mathrm{O} \cdots \mathrm{O}$ repulsions while the odd acids adopt a more strained twisted conformation to reduce these repulsions, which leads to easier accommodation of deformation during loading (reduced values of $E$ and $H$ ). Plastic deformation in diacids is explained by the sliding of molecular layers past each other depending on the interlayer separation distance. The hardest of examined diacids was succinic acid $\left(\mathrm{C}_{4}\right)$ with $H$ of $459.0 \mathrm{MPa}$ compared to glutaric acid $\left(\mathrm{C}_{5}\right)$ with $H$ of $135.1 \mathrm{MPa}$. During indentation, the strained lattice of odd acids facilitates long-range molecular migration, which reduces the overall strain in the lattice, resulting in higher plasticity. In addition, indents on odd acids showed more pile-up of material compared to the even one, indicating their higher plasticity. The differences in $H$ between odd and even acids decreased with increasing chain length, causing a decrease of the $H$ value in even acids and an increase of $H$ in odd acids $(100,101)$.

Nanoindentation was also used by Sanphui et al. in determining mechanical properties of voriconazole compared to its cocrystal and salt forms. It was demonstrated that $E$ and $H$ could be moderately modified by making salts and cocrystals. While the salt of voriconazole with hydrochloride acid was the stiffest, voriconazole was the softest among the tested compounds. The obtained nanoindentational results could be explained by the underlying structural properties. All the salt forms exhibited brittleness accompanied with strong ionic and other supplementary interactions, which is the reason for higher $E$ compared to voriconazole. Also, stronger ionic interactions in salt forms are the reason for stiffer properties of salt forms compared to weaker noncovalent interactions in cocrystals (102). The measured $E$ and $H$ values are summarized in Table III.

Chen and coworkers implemented the high-resolution total scattering pair distribution function (TS-PDF) analysis coupled with nanoindentation for assessment and prediction of disorders that can occur in API crystals when subjected to pharmaceutical unit operations like milling and compaction. They performed experiments on two pharmaceutical compounds. Compound 1 was a PARP (poly (ADP-ribose) polymerase) inhibitor evaluated as brittle, and compound 2 as a sphingosine-1-phosphate receptor agonist and antagonist as plastic material. Indentations were performed on dominant faces of at least two prepared single crystals. Much larger $E$ and $H$ were determined for compound 1 (10.4 and $0.4 \mathrm{GPa}$ ) compared to compound 2 (2.7 and $0.15 \mathrm{GPa}$ ). The fractured behavior of compound 1 was also aligned with pop-ins observed on the force-displacement curve during the loading, while for compound 2 pile-ups were noticed suggesting softer and plastic material. All these observations were also consistent with APIs' crystal structure. The molecules in compound 1 are cross-linked in a three-dimensional hydrogen-bond network exhibiting rigid isotropic lattice packing. The packing of compound 2 is anisotropic, where strong and weak interactions are present in nearly orthogonal directions typical of soft and plastic organic crystals. Their study was aimed at differentiating between the two compounds in their structural disorders that can arise in crystals upon milling and compaction. This was evaluated using the synchrotron-based high resolution total scattering pair distribution function analysis. No structural disorders were observed under typical milling and compaction conditions for the hard and brittle compound 1, whereas soft crystals of compound 2 exhibited obvious disorders even under mild milling and compaction conditions (103). 
It was recently reported that $H$ can be used as an effective parameter that correlates well with the solubility of compounds. Namely, both parameters depend on the same factors, i.e., crystal structure and intermolecular interactions. $H$ depends on the presence of slip planes and enhanced easiness of layers sliding past each other. This process requires breaking and re-establishment of intermolecular interactions. When less stress is required, the measured $H$ will be lower. The same principle can be foreseen for solubility. Solubility also depends on the ease with which intermolecular interactions can be broken, but instead of stress this is attained by the solvent. This claim was examined on curcumin and sulfathiazole, both of which exhibit several polymorphic forms with similar structure and small differences in melting points and in Gibbs free energy. It was determined that form 1 of curcumin was stiffer and harder with lower solubility compared to the other two polymorphic forms of curcumin with comparable but lower $E$ and $H$ and enhanced solubility. Comparing the deformational properties of four sulfathiazole polymorphs, it was established that form 1 was the least stiff and hard, whereas form 2 was the stiffest and hardest. The stability of polymorphic forms was ranked in the same order as $H$ but the differences in solubility were in the same order as differences in $H$ values. Inverse correlation was established between hardness and solubility, where the softest polymorph was also the most soluble. It was proposed that $H$ could be used as a parameter to assess the solubility order in close energy-related polymorphic systems (104).

Unusually large $E$ was reported for amino acid molecular crystals ( $\alpha$-glycine, L-alanine, DL-serine, glycylglycine). Values as high as $44 \mathrm{GPa}$ were measured with instrumented nanoindentation (Table III). It was shown that $E$ was strongly facet dependent and correlated with the underlying hydrogen-bonding network (105). Such a large $E$ of amino acid crystals had been previously obtained in high-pressure diffraction measurements $(106,107)$. The determined $E$ values of amino acids are remarkably high for molecular solids and suggest the hydrogen-bond network design as a pattern for rational design of ultra-stiff molecular solids (105).

\section{Nanoindentation in prediction of bulk mechanical properties}

Nanoindentation in milling prediction. - Particle-size reduction by mechanical means is a primary step for size distribution homogeneity, an important parameter for preventing segregation during mixing and tableting. Bioavailability of many poorly soluble drugs is enhanced if the primary particle size is reduced $(3,33)$. In general, fracture behavior of a material depends on its mechanical properties, processing conditions such as stress intensity, impact velocity and temperature, and the pre-existing imperfections and flaws in the material. Mechanical attributes of pharmaceutical materials usually investigated for evaluation of the particle breakage mechanism are the following: $E, H, B I$, and $K_{\mathrm{IC}}(33,86,87$, 89, 108-111). Mechanical properties that can be derived from these parameters are presented in Table II.

In a study performed by de Vegt et al., the effect of pre-existing flaws on mechanical properties of sodium chloride was investigated in order to improve control of the milling process. Sodium chloride was chosen because various sources and production methods offered the possibility of controlled variation in material defects. Defects were evaluated using an optical microscope and described as flaw density (flaws $\left./ \mathrm{m}^{2}\right)$ and average flaw size $(\mu \mathrm{m})$. The mechanical behavior of sodium chloride from various sources was evaluated by the $H /$ 
$P_{\mathrm{y}}$ ratio introduced by Roberts and Rowe (99). The $H / P_{\mathrm{y}}$ ratio is named the constraint factor and defines the ductility of the material. It was shown that particles exhibiting a small average flaw size or high flaw density had the lowest $H / P_{\mathrm{y}}$ ratio and were more prone to breakage. Particles with larger flaw size possess a high $H / P_{\mathrm{y}}$ and are more ductile and less susceptible to breakage. It was deduced that, besides processing conditions and material properties, particle fracture is more influenced by the number of flaws than by flaw length (109).

Meier et al. maintain that particle breakage is not simply a function of $H$ and $E$. In their experiment, several pharmaceutical excipients and APIs were mechanically evaluated (Table II). Ascorbic acid and sucrose had relatively high $H$ and high breakage affinity. On the other hand, acetylsalicylic acid also exhibited high breakage affinity but had the lowest $H$ of all the materials studied. It was demonstrated that $B I$ distinguished between breakage behaviors of the tested materials and confirmed its significant influence on particle-size reduction. Therefore, $B I$ was evaluated as a promising parameter for predicting milling behavior, which can be used for modeling and design of a milling process (33).

Taylor et al. succeeded in predicting milling behavior in large plant mills based on nanoindentation measurements on single crystals. Correlation was established between small- and large-scale milling behavior. Similar size reduction ratios were determined despite the differences in relative strain rates of the two processes. If $B I$ was higher, the percentage of size reduction was also higher (other milling parameters were constant). Among the five materials investigated, the most brittle one, sildenafil citrate (BI around 30), could be milled on any type of the standard mill equipment. For voriconazole, the most plastic and elastic material with $B I<1$, particle size below $250 \mu \mathrm{m}$, could not be obtained. It was deduced that more energy input was needed when a material is more elastically and plastically deformable; in these cases the material fractures at higher energy input. Thus, a more energetic milling process was required for voriconazole $(86,87)$.

Table II. Summary of experimental nanoindentation measurements in milling prediction

\begin{tabular}{|c|c|c|c|c|c|}
\hline Material & $E(\mathrm{GPa})$ & $H(\mathrm{GPa})$ & $\begin{array}{c}K_{\mathrm{IC}} \\
\left(\mathrm{MPa} \mathrm{m}^{1 / 2}\right)\end{array}$ & Mechanical properties & Reference \\
\hline $\begin{array}{l}\alpha \text {-Lactose } \\
\text { monohydrate }\end{array}$ & 21.44 & 0.869 & 0.0908 & \multirow{6}{*}{$\begin{array}{l}\text { Correlation exists } \\
\text { between } B I\left(H / K_{\mathrm{IC}}\right) \\
\text { and milling behavior }\end{array}$} & \multirow{6}{*}{33} \\
\hline Acetylsalicylic acid & 5.44 & 0.222 & 0.0211 & & \\
\hline Ascorbic acid & 34.46 & 1.003 & 0.0776 & & \\
\hline Sucrose & 12.6 & 1.013 & 0.1083 & & \\
\hline Tartaric acid & 3.5 & 1.354 & 0.1666 & & \\
\hline Glycine & 4.1 & 0.852 & 0.0978 & & \\
\hline Sildenafil citrate & 13.9 & 0.52 & 0.019 & \multirow{2}{*}{$\begin{array}{l}\text { Good correlation between } \\
B I \text { and milling behavior, } \\
\text { voriconazole more plastic, } \\
B I<1 \text {, difficult to mill; } \\
\text { sildenafil citrate more } \\
\text { brittle, } B I \sim 30 \text {, easy to mill }\end{array}$} & \multirow{2}{*}{86,87} \\
\hline Voriconazole & 3.7 & 0.13 & - & & \\
\hline
\end{tabular}


Nanoindentation as a tool for prediction of compaction behavior. - The state of art for predicting a powder's compression properties was set by Roberts and Rowe, who determined deformational properties of pharmaceutical materials according to $H, E$, and $P_{\mathrm{y}}$ with microindentation. Based on these parameters, the ability to form compacts was evaluated for some pharmaceutical excipients and APIs (99). Microindentation was also employed by Duncan-Hewit et al., who assessed $H, H / E$ ratio, and $K_{\text {IC }}$ of some pharmaceutical materials (i.e., sucrose, adipic acid, acetaminophen, and sodium chloride). They suggested that the $H / E$ ratio could be used to predict the behavior of materials during compaction; that is, a high $H / E$ ratio indicates poor compaction behavior. For example, in their study, acetaminophen had the highest $H / E$ ratio and also exhibited the poorest compaction behavior, enhanced by capping and lamination. Similar behavior was identified with adipic acid. In addition, higher values of $B I$ favored fragmentation of investigated materials during compaction, whereas lower values indicated ductile behavior, as demonstrated for sodium chloride (28).
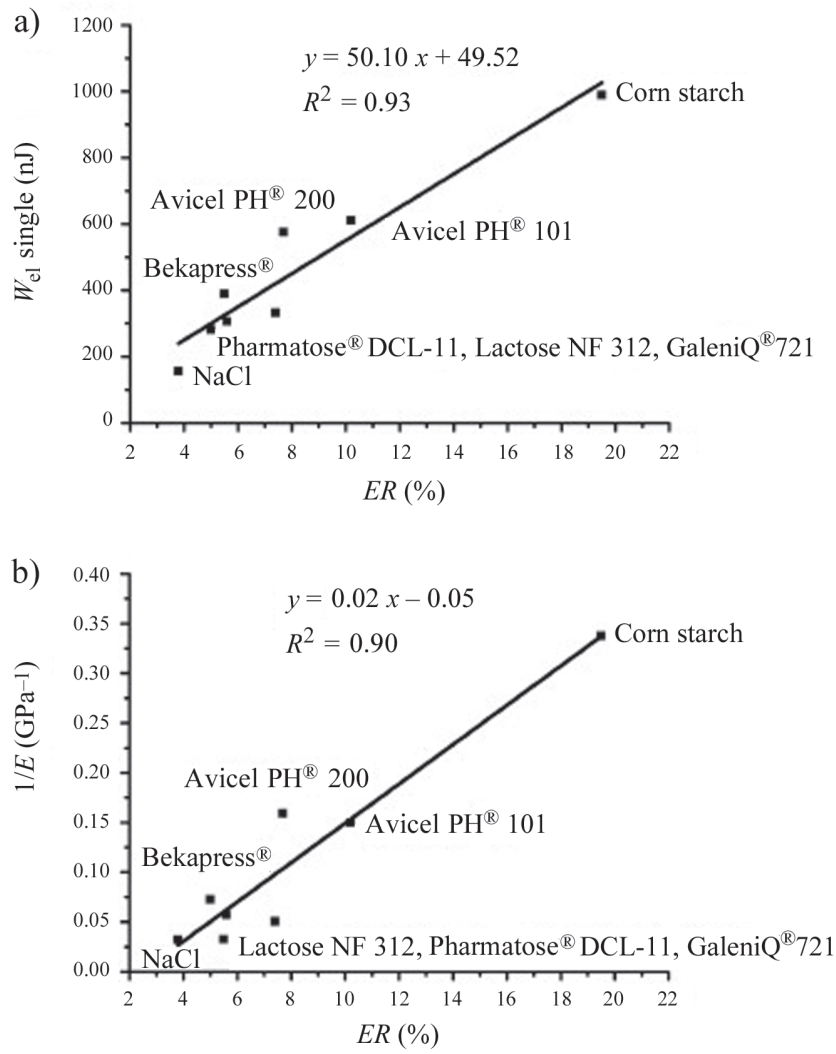

Fig. 7. Prediction of elastic deformation: correlation between $E R$ (elastic relaxation index - bulk level) and a) $W_{\text {el single }}$ (energy of elastic deformation) and b) $1 / E$ (compliance) (112) (with permission from Elsevier). 


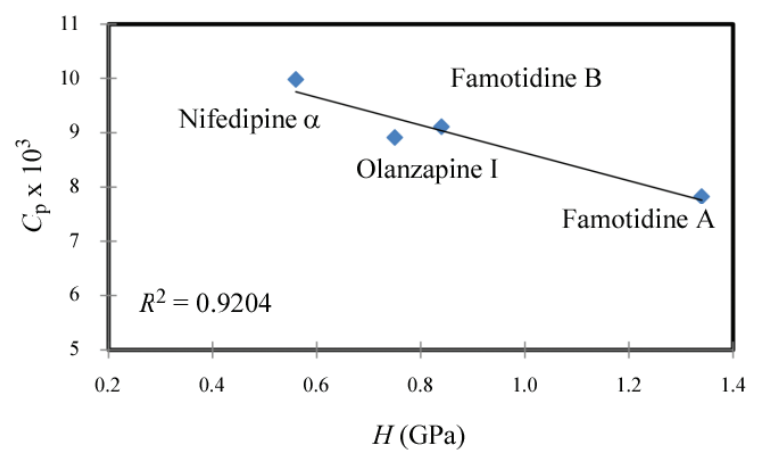

Fig. 8. Relationship between compactibility coefficients $\left(C_{\mathrm{p}}\right)$ and plasticity parameter-indentation hardness $(H)$ at the single-crystal level (62) (with permission from Elsevier).

Despite the aforementioned analysis using microindentation, the method is not commonly used for molecular crystals because it often leads to fracture. Extremely small and control loads are therefore needed, which can be accomplished with nanoindentation.

Govedarica et al. studied deformational behavior of common pharmaceutical excipients (microcrystalline cellulose, lactose, dicalcium phosphate anhydrous, corn starch, isomalt, and sodium chloride) by instrumented nanoindentation (112). The measured values are summarized in Table III. The main purpose was to categorize the deformational mechanisms of excipients at the single particle level as well as to predict compression behavior at the bulk level using Heckel and Walker coefficients. An excellent correlation was established between $H$ evaluating excipient's plasticity at the single level and the Walker coefficient (powder compressibility) at the bulk level. The energy of plastic deformation at the single particle level differentiated materials in which plastic deformation dominated (microcrystalline cellulose, corn starch) from those materials where brittle fracturing prevailed (lactose, dicalcium phosphate anhydrous). A material's elastic properties could be successfully predicted by measuring the energy of elastic deformation on a single scale $\left(W_{\text {el single }}\right)$ and compliance $(1 / E)$ because an excellent correlation was determined with the bulk parameters, such as energy of elastic deformation and the tablets' elastic relaxation index (Fig. 7).

In experiments performed by our group, the extent to which single-crystal mechanical properties of selected active ingredients (famotidine, nifedipine, olanzapine, piroxicam) influenced their bulk compressibility and compatibility was investigated. Nanoindentation experiments (values are given in Table III) were carried out on oriented single crystals in order to systematically evaluate the mechanical response of crystals with respect to their molecular structure (packaging). Good correlations were established between bulk and single-crystal plasticity parameters: the Walker coefficient and $H$. Moreover, it was possible to predict the elastic properties of the APIs investigated at the bulk level because a correlation between the elastic relaxation index and compliance $(1 / E)$ was established. In addition, compactibility of materials was successfully anticipated according to the $H$ values of single crystals (Fig. 8).

Most polymorphic forms investigated in our experiment exhibited mechanically interlocked structures, resulting in single crystals having isotropic mechanical properties (similar values of $E$ and $H$ determined at different crystal faces). It was shown that in such 
M. Egart et al.: Application of instrumented nanoindentation in preformulation studies of pharmaceutical active ingredients and excipients, Acta Pharm. 66 (2016) 303-330.

cases good correlations between single and bulk mechanical properties could be expected. The results implied that innate crystal deformational properties defined their powder compressibility and compactibility properties to a great extent (62).

Direct correlation was also established among crystal structure, mechanical behavior and tabletability in the three polymorphic forms of 6-chloro-2,4-dinitrianiline. The examined three polymorphic forms possessed different deformational mechanisms. Form I representing shearing, II bending and form III crystals are of brittle type. The tabletability (compactibility) of the three forms showed excellent agreement with the qualitative classification of plastic shearing, bending, and brittle nature determined according to Desiraju and co-workers $(50,96)$. According to the compactibility profile, it was shown that form III had substantially lower plasticity compared to the other two polymorphic forms, which could be expected also from their crystal structure. Form III has interlocked structure with relatively strong intermolecular interactions indicating its brittle structure. On the other hand, form I has thin flat 2D layers with relatively strong intralayer hydrogen bonds and weak non-specific stacking interactions between anti-parallel packed layers with larger spacing. These weakest planes act as slip systems for plastic shearing and thus stronger compacts can be made, as shown by the compactibility profile. Although the packing in form II is also of 2D type, its construction and interlayer interactions are different from those in form I. Strong intralayer and weak interlayer interactions are arranged in perpendicular direction required for all bending type crystals. Higher thickness of the sheets and superior strength of interlayer interactions are the cause of lower plasticity compared to form I. Prediction of plasticity according to nanoindentation $H$ could not be established because the crystals were not of sufficient size. However, the results reported by this research group suggest that the thinner the layers formed via strong interactions and the weaker the interlayer interactions, the higher is the plasticity of the crystals. In addition, the strength of the tablets is expected to be directly proportional to the strength of intermolecular interactions across the lowest energy slip plane in the crystal. This could be exploited to identify more efficient API formulation and manufacture (113).

Cocrystallization is considered as an effective tool for improving pharmaceutically relevant properties, e.g., improved physical and chemical stability, solubility, dissolution kinetics, bioavailability, product manufacturing as well as an opportunity for intellectual property $(11,12,50,58,114)$. Problems associated with the manufacturing performance can be anticipated by the nanoindentation technique, as shown in the presented examples. In a study performed by Chattoraj et al., a 1:1 molar ratio cocrystal was formed between piroxicam and saccharin. All three compounds (piroxicam, saccharin, cocrystal) were evaluated to find whether intact tablets could be made in the compression range between 10 and $300 \mathrm{MPa}$. The highest tensile strength was exhibited for saccharin, followed by piroxicam and cocrystal. This could be predicted by nanoindentational parameters determined on single crystals since $H$ was in the order saccharin $(0.49 \pm 0.01 \mathrm{GPa})<$ piroxicam $(0.53 \pm 0.20 \mathrm{GPa})<$ cocrystal $(0.63 \pm 0.04 \mathrm{GPa})$. Therefore, saccharin was most plastically deformable and also formed the strongest tablets over the compression range used in the study. On the other hand, the cocrystal could not form intact tablets (114).

In contrast, improved mechanical properties were obtained by formation of cocrystals between four vanillin isomers (vanillin, ethyl vanillin, iso-vanillin and Schiff base of ortho-vanillin with ethylene diamine) and 6-chloro-2,4-dinitroaniline. While single components displayed brittle nature, which was expected from their isotropic structures with three-dimensional interlocked packing, the cocrystals were less brittle. Crystal structures 
of cocrystals are stabilized by a combination of weak and strong interactions favoring plastic deformation. The highest tensile strength of tablets made from cocrystal powder was determined for the Schiff base of ortho-vanillin with ethylene diamine and 6-chloro2,4-dinitroaniline cocrystal, as already anticipated by nanoindentational deformational properties determined on single crystals (values are given in Table III) (115).

A summary of nanoindentational experiments for prediction of bulk compaction behavior is given in Table III.

\section{SUMMARY AND OUTLOOK}

Nanoindentation allows characterization of individual crystals or particles free of particle-particle interactions. Also, measurements can be performed quickly with little material, and as such can be very valuable for mechanical property screening in the early

Table III. Values of $\mathrm{E}$ and $\mathrm{H}$ obtained by nanoindentation measurements in predicting bulk compaction behavior

\begin{tabular}{|c|c|c|c|c|}
\hline Material & $E(\mathrm{GPa})$ & $H(\mathrm{GPa})$ & Mechanical properties & Reference \\
\hline Corn starch & $2.9 \pm 0.3$ & $0.225 \pm 0.013$ & plastic & \multirow{10}{*}{112} \\
\hline $\mathrm{NaCl}$ & $31.3 \pm 2.7$ & $0.373 \pm 0.055$ & plastic & \\
\hline Lactose NF 312 & $19.9 \pm 3.2$ & $1.128 \pm 0.117$ & brittle & \\
\hline Avicel ${ }^{\circledR}$ PH 200 & $6.3 \pm 0.8$ & $0.399 \pm 0.058$ & plastic & \\
\hline Avicel $^{\circledR}$ PH 101 & $6.7 \pm 0.5$ & $0.433 \pm 0.030$ & plastic & \\
\hline Pharmatose ${ }^{\circledR}$ DCL-11 & $17.5 \pm 1.4$ & $0.912 \pm 0.149$ & brittle & \\
\hline Bekapress $^{\circledR}$ & $30.8 \pm 2.5$ & $0.917 \pm 0.257$ & brittle & \\
\hline Famotidine A & $20.1 \pm 2.3$ & $1.34 \pm 0.23$ & brittle & \\
\hline Famotidine B & $19.5 \pm 0.4$ & $0.84 \pm 0.02$ & brittle/elastic & \\
\hline Nifedipine $\alpha$ & $12.3 \pm 5$ & $0.56 \pm 0.11$ & brittle/elastic & \\
\hline Olanzapine I & $14.4 \pm 1.7$ & $0.75 \pm 0.04$ & brittle/elastic & \multirow{2}{*}{62,98} \\
\hline Piroxicam I & $12.1 \pm 0.9$ & $0.61 \pm 0.08$ & brittle/elastic & \\
\hline Methyl paraben & & $1.41 \pm 0.44$ & \multirow{4}{*}{$\begin{array}{c}\text { Tensile strengths of } \\
\text { methyl, ethyl, propyl, and } \\
\text { butyl paraben are } 0.10 \mathrm{MPa} \text {, } \\
1.11 \mathrm{MPa}, 0.43 \mathrm{MPa} \text { and } \\
0.84 \text {, respectively. }\end{array}$} & \multirow{4}{*}{92} \\
\hline Ethyl paraben & & $0.312 \pm 0.089$ & & \\
\hline Propyl paraben & & $0.452 \pm 0.105$ & & \\
\hline Butyl paraben & & $0.514 \pm 0.068$ & & \\
\hline Succinic acid (C4) & & $0.459 \pm 0.005$ & \multirow{2}{*}{$\begin{array}{l}\text { Alternating mechanical } \\
\text { properties in } \alpha, \omega-\end{array}$} & \multirow{6}{*}{100} \\
\hline Glutaric acid (C5) & & $0.135 \pm 0.008$ & & \\
\hline Adipic acid (C6) & & $0.313 \pm 0.008$ & $\begin{array}{c}\text { alkanedicarboxylic acids. } \\
\text { Odd diacids exhibit }\end{array}$ & \\
\hline Pimelic acid (C7) & & $0.264 \pm 0.007$ & higher plasticity and & \\
\hline Suberic acid (C8) & & $0.295 \pm 0.005$ & \multirow{2}{*}{$\begin{array}{l}\text { elasticity compared to the } \\
\text { even ones. }\end{array}$} & \\
\hline Azelaic acid (C9) & & $0.259 \pm 0.004$ & & \\
\hline
\end{tabular}


M. Egart et al.: Application of instrumented nanoindentation in preformulation studies of pharmaceutical active ingredients and excipients, Acta Pharm. 66 (2016) 303-330.

\begin{tabular}{|c|c|c|c|c|}
\hline$\beta$-Piroxicam & $13.09 \pm 0.22$ & & \multirow{3}{*}{$\begin{array}{l}\text { Most plastically } \\
\text { deformable saccharin } \\
\text { exhibited the highest } \\
\text { tablet tensile strength. }\end{array}$} & \multirow[b]{3}{*}{114} \\
\hline Saccharin & $8.93 \pm 0.13$ & $0.49 \pm 0.01$ & & \\
\hline $\begin{array}{l}\text { Cocrystal ( } \beta- \\
\text { piroxicam/saccharin) }\end{array}$ & $20.31 \pm 1.19$ & $0.63 \pm 0.04$ & & \\
\hline Voriconazole & $3.79 \pm 0.17$ & $0.367 \pm 0.003$ & \multirow{7}{*}{$\begin{array}{l}\text { Voriconazole is } \\
\text { the softest among } \\
\text { tested compounds, } \\
\text { while hydrochloride } \\
\text { salt of voriconazole } \\
\text { is the hardest. }\end{array}$} & \multirow{7}{*}{102} \\
\hline $\begin{array}{l}\text { Voriconazole/HCl } \\
(1: 2) \text { salt }\end{array}$ & $19.41 \pm 0.13$ & $0.870 \pm 0.006$ & & \\
\hline $\begin{array}{l}\text { Voriconazole/oxalic } \\
\text { acid (1:1.5) salt }\end{array}$ & $5.95 \pm 0.10$ & $0.426 \pm 0.006$ & & \\
\hline $\begin{array}{l}\text { Voriconazole/oxalic } \\
\text { acid (1:1) salt }\end{array}$ & $8.29 \pm 0.25$ & $0.628 \pm 0.002$ & & \\
\hline $\begin{array}{l}\text { Voriconazole/fumaric } \\
\text { acid (1:1) cocrystal }\end{array}$ & $5.79 \pm 0.26$ & $0.293 \pm 0.003$ & & \\
\hline $\begin{array}{l}\text { Voriconazole/4-ami- } \\
\text { nobenzoic acid (1:1) } \\
\text { cocrystal }\end{array}$ & $5.63 \pm 0.35$ & $0.264 \pm 0.005$ & & \\
\hline $\begin{array}{l}\text { Voriconazole/4- } \\
\text { hydroxybenzoic acid } \\
\text { (1:1) cocrystal }\end{array}$ & $5.64 \pm 0.21$ & $0.263 \pm 0.002$ & & \\
\hline Curcumin form 1 & $11.15 \pm 0.20$ & $0.432 \pm 0.015$ & \multirow{7}{*}{$\begin{array}{l}\text { Inverse correlation } \\
\text { exists between } H \text { and } \\
\text { solubility. }\end{array}$} & \multirow{7}{*}{10} \\
\hline Cucumin form 2 & $5.68 \pm 0.25$ & $0.341 \pm 0.17$ & & \\
\hline Cucumin form 3 & $5.60 \pm 0.29$ & $0.333 \pm 0.018$ & & \\
\hline Sulfathiazole form 1 & $10.01 \pm 0.19$ & $0.356 \pm 0.010$ & & \\
\hline Sulfathiazole form 2 & $20.44 \pm 0.25$ & $1.080 \pm 0.015$ & & \\
\hline Sulfathiazole form 3 & $16.42 \pm 0.30$ & $0.704 \pm 0.018$ & & \\
\hline Sulfathiazole form 4 & $17.31 \pm 0.21$ & $0.881 \pm 0.012$ & & \\
\hline \multirow{4}{*}{$\alpha$-Glycine } & $26 \pm 1$ crystal face $(010)$ & & \multirow{10}{*}{$\begin{array}{l}E \text { of selected amino } \\
\text { acid molecular crystals } \\
\text { is facet-dependent and } \\
\text { correlates with the } \\
\text { underlying hydrogen- } \\
\text { bonding network. }\end{array}$} & \multirow{8}{*}{105} \\
\hline & $29 \pm 2$ crystal face $(110)$ & & & \\
\hline & $33 \pm 1$ crystal face $(011)$ & & & \\
\hline & $44 \pm 1$ crystal face $(001)$ & & & \\
\hline$\gamma$-Glycine & $28 \pm 1$ crystal face $(100)$ & & & \\
\hline \multirow{3}{*}{ L-Alanine } & $21.2 \pm 0.3$ crystal face $(010)$ & & & \\
\hline & $20.8 \pm 0.4$ crystal face $(120)$ & & & \\
\hline & $34.4 \pm 0.2$ crystal face $(011)$ & & & \\
\hline DL-serine & $23.1 \pm 0.5$ crystal face $(100)$ & & & \\
\hline Glycylglycine & $26 \pm 2$ crystal face $(001)$ & & & \\
\hline
\end{tabular}


stages of drug development. Sample properties are fundamental for obtaining relevant results. The best system for nanoindentation measurement are single crystals and particles, as well as polymeric films. The sample must be of sufficient size and quality. Nanoindentation parameters $E, H$, and $K_{\mathrm{IC}}$ can be utilized to determine a material's elasticity, plasticity, and fragmentation, which is important in all pharmaceutical processes in which material is exposed to stress, mainly during milling and tableting. It should be noted that nanoindentation focuses on particle mechanical properties, but other factors such as particle size, particle shape, particle interaction, lot-to-lot variation can have a significant effect when translating these properties to the bulk level (milling, compaction). Moreover, nanoindentation is useful for revealing the crystal structure and mechanical property relationships. These studies can aid crystal engineering in furthering the understanding of molecular crystal properties.

This review summarizes the usefulness of nanoindentation for testing small organic pharmaceutical substances and the role that these measurements have in predicting bulk mechanical properties. Important steps have already been made in ensuring reliability and usefulness of the data that can be obtained by nanoindentation. We believe that the growing interest in exploring the nano-level properties of materials will contribute to further development and utilization of the nanoindentation technique.

\section{REFERENCES}

1. B. B. Sheth, F. J. Bandelin, and R. F. Shangraw, Tablets, in Pharmaceutical Dosage Forms (Eds. H. A. Lieberman and L. Lachman), $1^{\text {st }}$ ed., Marcel Dekker, New York 1980, pp. 109-185.

2. P. Davies, Oral Solid Dosage Forms, in Pharmaceutical Preformulation and Formulation (Ed. M. Gibson), $2^{\text {nd }}$ ed., Informa Healthcare, Inc., New York 2009, pp. 367-430.

3. R. J. Roberts, Particulate Analysis: Mechanical properties, in Solid State Characterization of Pharmaceuticals (Eds. R. A. Storey and I. Ymen), $1^{\text {st }}$ ed., John Wiley \& Sons, Southern Gate UK 2011, pp. 357369.

4. J. Nordstrom, I. Klevan and G. Alderborn, A protocol for the classification of powder compression characteristics, Eur. J. Pharm. Biopharm. 80 (2012) 209-216 DOI: 10.1016/j.ejpb.2011.09.006.

5. G. E. Amidon, P. J. Secreast and D. Mudie, Particle, Powder, and Compact Characterization, in Developing Solid Dosage Forms (Eds. Y. Qiu, Y. Chen and G. G. Z. Zhang), $1^{\text {st }}$ ed., Elsevier, New York 2009, pp. 163-183.

6. C. Sun and D. J. W. Grant, Influence of crystal structure on the tableting properties of sulfamerazine polymorphs, Pharm. Res. 18 (2001) 274-280; DOI: 0724-8741/01/0300-0274.

7. S. Jain, Mechanical properties of powders for compaction and tableting: An overview PSST Vol. 2 (1999) 20-31; DOI: 10.1016/S1461-5347(98)00111-4.

8. D. Singhal and W. Curatolo, Drug polymorphism and dosage form design: a practical perspective, Adv. Drug Deliv. 56 (2004) 335-347; DOI: 10.1016/j.addr.2003.10.008.

9. S. F. Chow, M. Chen, L. Shi, A. H. L. Chow and C. C. Sun, Simultaneously improving the mechanical properties, dissolution performance, and hygroscopicity of ibuprofen and flurbiprofen by cocrystallization with nicotinamide, Pharm. Res. 29 (2012) 1854-1865; DOI: 10.1007/s11095-0120709-5.

10. A. Paradkar and P. York, Crystal Engineering and Particle Design for the Powder Compaction Process, in Pharmaceutical Powder Compaction Technology (Ed. M. Celik), $2^{\text {nd }}$ ed., Informa Healthcare, London 2011, pp. 235-252. 
11. N. Blagden, M. de Matas, P. T. Gavan and P. York, Crystal engineering of active pharmaceutical ingredients to improve solubility and dissolution rates, Adv. Drug Deliv. 59 (2007) 617-630; DOI: 10.1016/j.addr.2007.05.011.

12. S. Karki, T. Frišič, L. Fabian, P. R. Laity, G .M. Day and W. Jones, Improving mechanical properties of crystalline solids by cocrystal formation: New compressible forms of paracetamol, Adv. Mater. 21 (2009) 3905-3909; DOI: 10.1002/adma.200900533.

13. K. L. Johnson, Contact Mechanics (Ed. K. L. Johnson), $1^{\text {st }}$ ed., Cambridge University Press, Cambridge 1985.

14. N. E. Dowling, Mechanical Behaviour of Materials (Ed. N. E. Dowling), $1^{\text {st }}$ ed., Prentice-Hall Inc., New Jersey 1993.

15. K. L. Johnson, The correlation of indentation experiments, J. Mech. Phys. Solids 18 (1970) 115-125; DOI: 10.1016/0022-5096(70)90029-3.

16. R. C. Rowe and R. J. Roberts, Mechanical Properties, in Pharmaceutical Powder Compaction Technology (Eds. G. Alderborn and C. Nystrom), $1^{\text {st }}$ ed., Marcel Dekker Inc, New York 1996, pp. $283-322$.

17. S. W. Hoag, V. S. Dave and V. Moolcandani, Compression and Compaction, in Pharmaceutical Dosage Forms - Tablets (Eds. L. L. Augsburger and S. W. Hoag), $3^{\text {rd }}$ ed., Taylor \& Francis Group, New York 2008, pp. 555-631.

18. S. Finnie, K. V. R. Prasad, D. B. Sheen and J. N. Sherwood, Microhardness and dislocation identification studies on paracetamol single crystals, Pharm. Res. 18 (2001) 674-681; DOI: 07248741/01/0500-0674.

19. M. Radovic, E. Lara-Curzio and L. Riester, Comparison of different experimental techniques for determination of elastic properties of solids, Materials Sci. Engin. A368 (2004) 56-70; DOI: 10.1016/j. msea.2003.09.080.

20. R. W. Heckel, An analysis of powder compaction phenomena, Trans. Metall. Soc. AIME 221 (1961a) 1001-1008.

21. R. W. Heckel, Density-pressure relationships in powder compaction, Trans. Metall. Soc. AIME 221 (1961b) 671-675.

22. E. E. Walker, The properties of powders VI: The compressibility of powders. Trans. Faraday Soc. 19 (1923) 73-82; DOI: 0.1039/tf9231900073.

23. K. Kawakita and K. H. Ludde, Some consideration on powder compression equations, Powder Technol. 4 (1971) 61-68; DOI: 10.1016/0032-5910(71)80001-3.

24. M. J. Adams, M. A. Mullier and J. P. K. Seville, Agglomerate strength measurement using a uniaxial confined compression test, Powder Technol. 78 (1994) 5-13; DOI: 140.1016/0032-5910(93)02777-8.

25. J. S. Smith, M. D. Wyrick and J. M. Poole, An evaluation of three techniques for determining Young's modulus of mechanically alloyed materials. Dynamic Elastic Modulus Measurements in Materials, ASTM (1990) 195-206; DOI: 10.1520/STP24625S.

26. Standard Test Method for Young's Modulus, Shear Modulus, and Poisson's Ratio for Glass and Glass-Ceramics by Resonance, Annual Book of ASTM Standards 15 (2006) 623-692.

27. N. A. Armstrong and R. F. Haines-Nutt, Elastic recovery and surface area changes in compacted powder systems, J. Pharm. Pharmacol. 24 (1972) 138-136; DOI: 10.1016/0032-5910(74)80054-9.

28. W. C. Duncan-Hewitt and G. C. Weatherly, Evaluating the hardness, Young's modulus and fracture toughness of some pharmaceutical crystals using microindentation techniques, J. Mater. Sci. 8 (1989) 1350-1352; DOI: 0261-8028/89.

29. M. Celik, Pharmaceutical Powder Compaction Technology, $2^{\text {nd }}$ ed., Informa Healthcare, New York 2011.

30. X. Cao and M. A. Morganti, Study of Hiestand's "Special Case" Pharmaceutical Materials Using AFM Nanoindentation, 2009, AAPS Annual Meeting and Exposition. 
M. Egart et al:: Application of instrumented nanoindentation in preformulation studies of pharmaceutical active ingredients and excipients, Acta Pharm. 66 (2016) 303-330.

31. D. Olusanmi, K. J. Roberts, M. Ghadiri and Y. Ding, The breakage behaviour of Aspirin under quasi-static indentation and single particle impact loading: Effect of crystallographic anisotropy, Int. J. Pharm. 411 (2011) 49-63; DOI: 10.1016/j.ijpharm.2011.03.039.

32. C. C. Kwan, Y. Q. Chen, Y. L. Ding, D. G. Papadopoulos, A. C. Bentham and M .Ghadiri, Development of a novel approach towards predicting the milling behaviour of pharmaceutical powders, Eur. J. Pharm. Sci. 23 (2004) 327-336; DOI: 10.1016/j.ejps.2004.08.006.

33. M. Meier, E John, D. Wieckhusen, W. Wirth and W. Peukert, Influence of mechanical properties on impact fracture: Prediction of the milling behaviour of pharmaceutical powders by nanoindentation, Powder Technol. 188 (2009) 301-313; DOI: 101016/j.powtec.2008.05.009.

34. V. M. Masterson and X. Cao, Evaluating particle hardness of pharmaceutical solids using AFM nanoindentation, Int. J. Pharm. 362 (2008) 163-171; DOI: 10.1016/j.ijpharm.2008.06.015.

35. A. C. Fischer-Cripps, Nanoindentation, $3^{\text {rd }}$ ed., Springer Verlag, New York 2011.

36. X. Liao and T. S. Wiedmann, Measurement of process-dependent material properties of pharmaceutical solids by nNanoindentation, J. Pharm. Sci. 94 (2004) 79-92; DOI: 10.1002/jps.20227.

37. S. Varughese, M. S. R. N. Kiran, K. A. Solanko, A. D. Bond, U. Ramamurty and G. R. Desiraju, Interaction anisotropy and shear instability of aspirin polymorphs established by nanoindentation, Chem. Sci. 2 (2011) 2236-2242; DOI: 10.1039/c1sc00430a.

38. S. R. Cohen and E. Kalfon-Cohen, Dynamic nanoindentation by instrumented nanoindentation and force microscopy: a comparative review, Beilstein J. Nanotechnol. 4 (2013) 815-833; DOI: 10.3762/ bjnano.4.93.

39. E. H. H. Chow, D. K. Bučar and W. Jones, New opportunities in crystal engineering: The role of atomic force microscopy in studies of molecular crystals, Chem. Comm. 48 (2012) 9210-9226; DOI: $10.1039 / \mathrm{c} 2 \mathrm{cc} 32678 \mathrm{~g}$.

40. E. V. Boldyreva, High-pressure diffraction studies of molecular organic solids. A personal view, Acta Cryst. A64 (2008) 218-231; DOI: 10.1107/S0108767307065786.

41. F. P. A. Fabbiani and C. R. Pulham, High-pressure studies of pharmaceutical compounds and energetic materials, Chem. Soc. Rev. 35 (2006) 932-942; DOI: 10.1039/B517780B.

42. T. P. Shakhtshneider, E. V. Boldyreva, M. A. Vasilchenko, H. Ahsbahs and H. Uchtmann, Anisotropy of crystal structure distortion in organic molecular crystals of drugs induced by hydrostatic compression, J. Struct. Chem. 40 (1999) 892-898; DOI: 0022-4766/99/4006-0892.

43. E. V. Boldyreva, T. P. Shakhtshneider, M. A. Vasilchenko, H. Ahsbahs and H. Uchtmann, Anisotropic crystal structure distortion of the monoclinic polymorph of acetaminophen at high hydrostatic pressure, Acta Cryst. B56 (2000) 299-309; DOI: 10.1107/s0108768199013634.

44. T. Beyer, G. M. Day and S. L. Price, The prediction, morphology, and mechanical properties of the polymorphs of paracetamol, J. Am. Chem. Soc. 123 (2001) 5086-5094; DOI: 10.1021/ja0102787.

45. M. H. Shariare, F. J. J. Leusen, M. De Matas, P. York and J. Anwar, Prediction of the mechanical behavior of crystalline solids, Pharm. Res. 29 (2012) 319-331; DOI: 10.1007/s11095-011-0543-1.

46. C. C. Sun and Y. H. Kiang, On the identification of slip planes in organic crystals based on attachment energy calculation, J. Pharm. Sci. 97 (2007) 3456-3461; DOI: 10.1002/jps.21234.

47. M. J. Turner, S. P. Thomas, M. W. S. D. Jayatilaka and M. A. Spackman, Energy frameworks: insights into interaction anisotropy and the mechanical properties of molecular crystals, Chem. Commun. 51 (2015) 3735-3738; DOI: 10.1039/c4cc09074h.

48. W. C. Oliver and G. M. Pharr, An improved technique for determining hardness and elastic modulus using load and displacement sensing indentation measurements, J. Mater. Res. 7 (1992) 15641583; DOI: 10.1557/JMR.1992.1564.

49. W. C. Oliver and G. M. Pharr, Measurement of hardness and elastic modulus by instrumented indentation: Advances in understanding and refinements to methodology, J. Mater. Res. 19 (2004) 3-20; DOI: 10.1557/jmr.2004.0002. 
M. Egart et al:: Application of instrumented nanoindentation in preformulation studies of pharmaceutical active ingredients and excipients, Acta Pharm. 66 (2016) 303-330.

50. C. M. Reddy, G. R. Krishna and S. Ghosh, Mechanical properties of molecular crystals: Applications to crystal engineering, Cryst. Eng. Comm. 12 (2010) 2296-2314; DOI: 10.1039/c003466e.

51. U. Ramamurty and J. Jang, Nanoindentation for probing the mechanical behavior of molecular crystals: A review of the technique and how to use it, Cryst. Engin. Comm. 16 (2014) 12-23; DOI: $10.1039 / \mathrm{c} 3 \mathrm{ce} 41266 \mathrm{k}$.

52. D. A. Lucca, K. Herrmann and M. J. Klopfstein, Nanoindentation: Measuring methods and applications, Manuf. Tech. 59 (2010) 803-819; DOI: 10.1016/j.cirp.2010.05.009.

53. http://www.csm-instruments.com/ Why is Nanoindentation more quantitative than AFM for measurement of surface mechanical properties?; access date January 25, 2014.

54. X. Li and B. Bhushan, A review of nanoindentation continuous stiffness measurement technique and its application, Mater. Charact. 48 (2002) 11-36; DOI: org/10.1016/S1044-5803(02)00192-4.

55. S. P. Baker, Nanoindentation Techniques, in Encyclopedia of materials: Science and Technology (Eds. K. H. J. Buschow, R. C. Cahn, M. C. Flemings, B. Ilschner, E.J. Kramer and S. Mahajan), Elsevier, New York 2001, pp. 5908-5915.

56. Agilent Technologies, How to select the correct indenter tip, Agilent Technologies, Inc. 2009, USA.

57. CSM Instruments, Nanoindentation approach to mechanical testing of extremely soft materials, CSM Instruments, No 35, June 2011, Switzerland.

58. S. Varughese, M. S. R. N. Kiran, U. Ramamurty and G. R. Desiraju, Nanoindentation in crystal engineering: quantifying mechanical properties of molecular crystals, Angew. Chem. Int. Ed. 52 (2013) 2701-2712; DOI: 10.1002/anie.201205002.

59. C. A. Schuh, Nanoindentation studies of materials, Materials Today 9 (2006) 32-40; DOI: 10.1016/ S1369-7021(06)71495-X.

60. A. C. Fischer-Cripps, Critical review of analysis and interpretation of nanoindentation test data, Surface \& Coatings Tech. 200 (2006) 4153-4165; DOI: 10.1016/j.surfcoat.2005.03.018.

61. E. Rettler, S. Hoeppener, B. W. Sigusch and U. S. Schubert, Mapping the mechanical properties of biomaterials on different length scales: depth-sensing indentation and AFM based nanoindentation, J. Mater. Chem. B1 (2013) 2789-2806; DOI: 10.1039/c3tb20120a.

62. M. Egart, I. Ilić, B. Janković, N. Lah and S. Srčič, Compaction properties of crystalline pharmaceutical ingredients according to the Walker model and nanomechanical attributes, Int. J. Pharm. 472 (2014b) 347-355; DOI: 10.1016/j.ijpharm.2014.06.047.

63. http://www.iso.org/iso/iso_catalogue/catalogue_tc/catalogue_detail.htm?csnumber=3054; access date June 20, 2013.

64. http://www.astm.org/Standards/E2546.htm.

65. Agilent Nano Indenter G200, User's Guide, Agilent Technologies, 2009.

66. Agilent Technologies, Nanoindentation, scratch, and elevated temperature testing of cellulose and PMMA films, Agilent Technologies, Inc. 2010, USA.

67. H. Hertz, Über die Berührung fester elastischer Körper, J. Reine Angew. Mathematik 92 (1894) 156171.

68. T. Chudoba and F. Richter, Investigation of creep behavior under load during indentation experiments and its influence on hardness and modulus results, Surface Coatings Technol. 148 (2001) 191-198; DOI: 10.1016/S0257-8972(01)01340-8.

69. G. Feng and A. H. W. Ngan, Effects of creep and thermal drift on modulus measurement using depth-sensing indentation, J. Mater. Res. 17 (2002) 660-668; DOI: 010.1016/j.actbio.2014.08.004.

70. I. N. Sneddon, The relation between load and penetration in the axisymmetric Boussinesq problem for a punch of arbitrary profile, Int. J. Eng. Sci. 3 (1965) 47-57; DOI: 10.1016/0020-72225(65)900019-4.

71. K. J. Ramos and D. F. Bhar, Mechanical behavior assessment of sucrose using nanoindentation, J. Mater. Res. 7 (2007) 2037-2045; DOI: 10.1557/JMR.2007.0249. 
M. Egart et al:: Application of instrumented nanoindentation in preformulation studies of pharmaceutical active ingredients and excipients, Acta Pharm. 66 (2016) 303-330.

72. M. L. Malkowska and K. A. Khan, Effect of recompression on the properties of tablets prepared by dry granulation, Drug. Dev. Ind. Pharm. 9 (1983) 331-347; DOI: 10.3109/03639048309044678.

73. S. Inghelbrecht and J. P. Remon, Roller compaction and tableting of microcrystalline cellulose/ drug mixtures, Int. J. Pharm. 161 (1998) 215-224; DOI: 10.1016/S0378-5173(97)00356-6.

74. J. Lee, Structural heterogeneity of pharmaceutical compacts probed by micro-indentation, J. Mater. Sci.: Mater. Med. 19 (2008) 1981-1990; DOI: 10.1007/s10856-007-3283-3.

75. A. Bolshakov and G. M. Pharr, Influences of pile-up on the measurement of mechanical properties by load and depth sensing indentation techniques, J. Mater. Res. 13 (1998) 1049-1058; DOI: 104910.1557/JMR.1999.0303.

76. J. Hay, Introduction to instrumented indentation testing, Experim. Tech. (2009) 66-72; DOI: 10.1111/j. 1747-1567.2009.00541.x.

77. Y. Huang, F. Zhang, K. C. Hwang, W. D. Nix, G. M. Pharr and G. Feng, A model of size effects in nano-indentation, J. Mech. Phys. Solids 54 (2006) 1668-1686; DOI: 10.1016/j.jmps.2006.02.002.

78. K. Sangwal, Review: Indentation size effect, indentation cracks and microhardness measurement of brittle crystalline solids - some basic concepts and trends, Cryst. Res. Technol. 44 (2009) 10191037; DOI: 10.1002/crat.200900385.

79. W. D. Nix and H. Gao, Indentation size effects in crystalline materials: a law for strain gradient plasticity, J. Mech. Phys. Solids 46 (1998) 411-425; DOI: S0022-5096(97)00086-0.

80. Agilent Technologies, Indentation rules of thumb: Applications and limits, Agilent Technologies, Inc. 2010, USA.

81. http://cp.literature.agilent.com/litweb/pdf/5990-5700EN.pdf; Indentation rules of thumb-Applications and Limits, Agilent Technologies; access date October 25, 2015.

82. http://www.iso.org/iso/catalogue_detail.htm?csnumber=30104; Metallic materials-Instrumented indentation test for hardness and materials parameters. ISO 14577-1: 2002; access date October 23, 2015.

83. http://www.nanomechanicsinc.com/index.php/Service-Lab/sample-preparation.html; access date October 25, 2015.

84. http://www.csm-instruments.com/ The influence of surface roughness on instrumented indentation testing (IIT); access date January 25, 2014.

85. K. I. Schiffmann, Determination of fracture toughness of bulk materials and thin films by nanoindentation: comparison of different models, Philosoph. Magazine 91 (2011) 1163-1178; DOI: 10.1080/14786435.2010.487984.

86. L. J. Taylor, D. G. Papadopoulos, P. J. Dunn, A. C. Bentham, J. C. Mitchell and M. J. Snowden, Mechanical characterization of powders using nanoindentation, Powder Tech. 143-144 (2004) 179-185; DOI: 10.1016/j.powtec.2004.04.012.

87. L. J. Taylor, D. G. Papadopoulos, P. J. Dunn, A. C. Bentham, N. J. Dawson, J. C. Mitchell and M. J. Snowden, Predictive milling of pharmaceutical materials using nanoindentation of single crystals, Org. Process Res. Dev. 8 (2004) 674-679; DOI: 10.1021/op0300241.

88. http://cdn.intechweb.org/pdfs/16971.pdf; access date October 25, 2015.

89. M. Ghadiri and Z. Zhang, Impact attrition of particulate solids. Part 1: A theoretical model of chipping, Chem. Engin. Sci. 57 (2002) 3659-3669; DOI: 0009-2509(02)00240-3.

90. B. R. Lawn and D. B. Marshall, Hardness, toughness and brittleness: An indentation analysis, J. Am. Ceram. Soc. 62 (1979) 347-350.

91. R. V. Haware, P. Kim, L. Ruffino, B. Nimi, C. Fadrowsky, M. Doyle, S. W. X. M. Boerrigter, A. Cuitino and K. Morris, Anisotropic crystal deformation measurements determined using powder X-ray diffraction and a new in situ compression stage, Int. J. Pharm. 418 (2011) 199-206; DOI: 10.1016/j.ijpharm.2011.06.021. 
M. Egart et al.: Application of instrumented nanoindentation in preformulation studies of pharmaceutical active ingredients and excipients, Acta Pharm. 66 (2016) 303-330.

92. Y. Feng and D. J. W. Grant, Influence of crystal structure on the compaction properties of n-alkyl 4-hydrokxybenzoate esters (parabens), Pharm. Res. 23 (2006) 1608-1616; DOI: 10.1007/s11095-0060275-9.

93. S. E. David, M. Ramirez, P. Timmins and B. R. Conway, Comparative physical, mechanical and crystallographic properties of a series of gemfibrozil salts, J. Pharm. Pharmacol. 62 (2010) 15191525; DOI: 10.11117j.2042-7158.2010.01025.x.

94. Y. Feng, J. W. Grant and C. C. Sun, Influence of crystal structure on the tableting properties of n-alkyl 4-hydroxybenzoate esters (parabens), J. Pharm. Sci. 96 (2007) 3324-3333; DOI: 10.1002/ jps.20981.

95. R. Bandyopadhyay and D. J. W. Grant, Plasticity and slip system of plate-shaped crystals of Llysine monohydrochloridedihydrate, Pharm. Res. 19 (2002) 491-496; DOI: 0724-8741/02/04000491/0.

96. C. M. Reddy, K. A. Padmanabhan and G. R. Desiraju, Structure-property correlations in bending and brittle organic crystals, Cryst. Growth Des. 6 (2006) 2720-2731; DOI: 10.1021/cg060398w.

97. M. S. R. N. Kiran, S. Varughese, C. M. Reddy, U. Ramamurty and G. R. Desiraju, Mechanical anisotropy in crystalline saccharin: nanoindentation studies, Cryst. Growth Des. 10 (2010) 46504655; DOI: 10.1021/cg1009362.

98. M. Egart, B. Janković, N. Lah, I. Ilić and S. Srčič, Nanomechanical properties of selected single pharmaceutical crystals as a predictor of their bulk behaviour, Pharm. Res. 32 (2015) 469-481; DOI: 10.1007/s11095-014-1475-3.

99. R. J. Roberts and R. C. Rowe, The compaction of pharmaceutical and other model materials: a pragmatic approach, Chem. Eng. Sci. 42 (1987) 903-911; DOI: 009-2509/87.

100. M. K. Mishra, U. Ramamurty and G. R. Desiraju, Hardness alternation in $\alpha, \omega$-alkanedicarboxylic acids, Chem. Asian J. 10 (2015) 2176-2181; DOI: 10.1002/asia.201500322.

101. M. K. Mishra, S. Varughese, U. Ramamurty, and G. R. Desiraju, Odd-even effect in the elastic moduli of $\alpha, \omega$-alkanedicarboxylic acids, J. Am. Chem. Soc. 135 (2013) 8121-8124; DOI: 10.1021/ ja402290hl.

102. P. Sanphui, M. K. Mishra, U. Ramamurty and G. R. Desiraju, Tuning mechanical properties of pharmaceutical crystals with multicomponent crystals: voriconazole as a case study, Mol. Pharmaceutics 12 (2015) 889-897; DOI: 10.1021/mp500719t.

103. S. Chen, A. Y. Sheikh and R. Ho, Evaluation of effects of pharmaceutical processing on structural disorders of active pharmaceutical ingredient crystals using nanoindentation and highresolution total scattering pair distribution function analysis, J. Pharm. Sci. 103 (2014) 3879-3890; DOI: 10.1002/jps.24178.

104. M. K. Mishra, P. Sanphui, U. Ramamurty and G. R. Desiraju, Solubility-hardness correlation in molecular crystals: curcumin and sulfathiazole polymorphs, Cryst. Growth Des. 14 (2014) 30543061; DOI: $10.1021 / \operatorname{cg} 500305$.

105. I. Azuri, E. Meirzadeh, D. Ehre, S. R. Cohen, A. M. Rappe, M. Lahav, I. Lubomirsky and L. Kronik, Unusually large Young's moduli of amino acid molecular crystals, Angew. Chem. Int. Ed. 54 (2015) 1-6; DOI: 10.1002/anie.201505813.

106. B. A. Zakharov, B. A. Kolesov and E. V. Boldyreva, Effect of pressure on crystalline L- and DLserine: revisited by a combined single-crystal X-ray diffraction at a laboratory source and polarized Raman spectroscopy study, Acta Cryst. B68 (2012) 275-286; DOI: 10.1107/s0108768112015960.

107. C. Murli, S. M. Sharma, S. Karmakar and S. K. Sikka, $\alpha$-glycine under high pressures: a Raman scattering study, Physica B339 (2003) 23-30; DOI: 10.1016/S0921-4526(03)00446-0.

108. S. Zugner, K. Marquardt and I. Zimmerman, Influence of nanomechanical crystal properties on the comminution process of particulate solids in spiral jet mills, Eur. J. Biopharm. Pharm. 62 (2006) 194-201; DOI: 10.1016/j.ejpb.2005.08.002. 
M. Egart et al:: Application of instrumented nanoindentation in preformulation studies of pharmaceutical active ingredients and excipients, Acta Pharm. 66 (2016) 303-330.

109. O. Vegt, H. Vromans, J. Toonder and K. Voort Maarschalk, Influence of flaws and crystal properties on particle fracture in a jet mill, Powder Technol. 191 (2009) 72-77; DOI: 10.1016/j.powtec.2008.09.014.

110. L. Vogel and W. Peukert, Breakage behaviour of different materials-construction of a master curve for the breakage probability, Powder Technol. 129 (2003) 101-110; DOI: 10.1016/S00325910(02)00217-6.

111. L. Vogel and W. Peukert, From single particle impact behavior to modeling of impact mills, Chem. Engin. Sci. 60 (2005) 5164-5176; DOI: 10.1016/j.ces.2005.03.064.

112. B. Govedarica, I. Ilić, R. Šibanc, R. Dreu and S. Srčič, The use of single particle mechanical properties for predicting the compressibility of pharmaceutical materials, Powder Technol. 225 (2012) 43-51; DOI: 10.1016/j.powtec.2012.03.030.

113. P. P. Bag, M. Chen, C. C. Sun and C. M. Reddy, Direct correlation among crystal structure, mechanical behaviour and tabletability in a trimorphic molecular compound, Cryst. Eng. Comm. 14 (2012) 3865-3867; DOI: 10.1039/c2ce25100k.

114. S. Chattoraj, L. Shi, M. Chen, A. Alhalaweh, S. Velaga and C. C. Sun, Origin of deteriorated crystal plasticity and compaction properties of a 1:1 cocrystal between piroxicam and saccharin, Cryst. Growth Des. 14 (2014) 3864-3874; DOI: 10.1021/cg500388s.

115. G. R. Krishna, L. Shi, P. P. Bag, C. C. Sun and C. M. Reddy, Correlation among crystal structure, mechanical behavior, and tabletability in the co-crystals of vanillin isomers, Cryst. Growth Des. 15 (2015) 1827-1832; DOI: 10.1021/cg5018642. 